\title{
Digital Library and Web 3.0
}

\author{
H A Karibasappa \\ Librarian \\ Government First Grade College \\ Harihara \\ Davanagere - District \\ Karnataka
}

\begin{abstract}
The expanding measure of information accessible online is changing the sort of information grouping and access. Given the huge assortment of information put away on the web, the advanced library is a principle subject of examination. In the midst of the difficulties of arranging, finding and getting to information in computerized libraries, which improves web libraries through various procedures, improves advanced libraries through various methodologies, specifically, semantics. Use stays a promising and intriguing methodology. All through this paper, Callimachus DL is presented, a semantic-based computerized library that gives a logo to vocal hunt, improved prospects, and idea usage. The Calimachus DL speaks to a totally interesting way to deal with advanced libraries, coordinating social web and mixed media components into an abundant commented on storehouse. Execution results recommend that the highlights proposed in Calimachus DL are empowering and expandable inside the utilization of computerized libraries.
\end{abstract}

Keywords:- Digital Library. Semantic Web. Compilation. Faced Search.

\section{INTRODUCTION}

The advanced library speaks to the re-establishment of programming applications that expect to give order, grouping, chronicling, and admittance to tremendous heavenly bodies of web assets. Presently, advanced libraries are confronting another move to conquer different difficulties, for example, customary perusing or watchword based methodologies. In a general sense, DL framework improvement endeavors look to build the nature of data recovery, from question organization to community sifting or adaptable perusing. Notwithstanding, current arrangements despite everything don't meet desires, which as a rule can prompt customer dissatisfaction. The DL's space isn't disregarded during improvement.

Semantic Web. Semantics in DL utilize current information to powerfully find open information and drawings in a DL structure, which is obliged by the dependence on transient, task-explicit systems of current DL advancements. On this paper.
The Kalimachus DL is introduced as a semantic-based DL that improves semantic data and perusing search and recovery. One of the real factors of our work is the incorporation of social web media mainland Earth comments as a feature of DL. The remainder of the paper is sorted out as follows. Segment 2 gives an outline of the best in class. In Section 3, a few necessities are talked about and the advantages of comprehending them with a superior methodology are introduced. Kalimachus DL is portrayed in detail in Section 4, alongside confirmation of its structure and idea usage. Area 5 presents the trial arrangement for Kalimachus DL. At long last, Section 6 sums up the paper giving and future work.

\section{A. Digital Library}

DLs give high caliber and smoothed out data. Numerous ground-breaking highlights of DL rely upon metadata. To give data productively, custodians depict assets through inventories and different assortments. The utilization of metadata in its organizations and usefulness is an item concentrate in the field of DL previously, for instance DL utilizing oncology with regards to XML and RDF, interrelationships by portraying new capacities. The idea of oncology presented by the Semantic Web is a decent method to broaden DL conventions with comments, and Sevalthorors' oncology has been proposed to clarify all parts of the DL situation by various boundaries of DL portrayal configurations, for example, MARC21, And Bibtex are past the Dublin center. .

The new and expected DLS content administration apparatus age originates from a mix of new social components known as the Semitic Web and the Social Web. Hireseveral activities, for example, the aspiring Jeromedalproject or Delibra can be met. JeromedL utilizes Markent Ontology, which utilizes a few inheritance metadata principles (MARC21, Bibtex and Dublin Core) and gives various exploratory recovery administrations dependent on semantic innovation. On a very basic level, the Calimachus DL approach varies from the one portrayed before, since semantic route was proposed, utilizing vis-àvis search and perusing, metadata-delivering designs, and the general methodology as the fundamental structure standard. Those highlights are portrayed in the following segment. 


\section{B. Web Technologies}

Semantic web innovations are not simply some proposed arrangements, they are turning out to be one Reality and various different backgrounds are utilizing them:

$>$ Semantic Wiki

$>$ Semantic Blog

$>$ Semantic Digital Library

\section{Past: Digital Library (DL)}

PCs have rolled out progressive improvements in each circle of life; Undoubtedly, the field of training and data is the same. Critically, conventional libraries conveyed forward the idea of computerized libraries, which inevitably made information more effective and composed. Notwithstanding, an eminent significant reality here is that the advanced library ought to be more [26] than a smoothed out concentrated type of data. Furthermore, they ought to likewise catch the quintessence of correspondence, which was initially a part of vis-à-vis cooperation between individuals in a customary library.

\section{$>$ Benefit}

- People can get the fundamental data whenever of the day, as long as they have web LOSS.

- Search isn't proficient, as it can't give important information to the client because of its orders. As a rule, admittance to certain data is restricted by copyright law

- information is static; Therefore, no client can contribute their perspectives or offer their insight with different members.

\section{$>S D L$ to $D L$}

After the approach of computerized libraries in our carries on with, another inventive advance followed. This progression was made corresponding to making search more significant and direct. Basically, it was identified with dodging the propensity for discovering all things 'all over'. The development of Web 2.0 has offered ascend to better approaches for getting to data and contributing feelings. Specifically, semantic advanced libraries empower the client to get the ideal data identified with an item without the nearness of the specific word in the pursuit. This coordinated type of data depends on different metadata that give more important information. These libraries give a superior and helpful type of perusing interface.

\section{* Improvement of Semantic Digital Libraries}

\section{$>$ Benefit}

- Semantic computerized library makes it simple to discover data in the huge expanse of accessible information. It is encouraged by oncology-based disclosure and perspective finding.

- Access isn't restricted to only one advanced library; actually, it gives an arrangement of contrasts between various frameworks.

\section{$>$ The Loss}

- Existing metadata of computerized libraries should be taken to the semantic level.

- Not every single computerized library, government organizations, and so forth look after metadata.

- Current Earth Digital Library System

- A portion Of The Semantic Digital Library Systems Are:

$\checkmark$ SIMILE3: This framework centers around expanding the coordination part of metadata, administrations, and so forth to build availability.

$\checkmark$ Geromedal: A social significance can be viewed as a computerized library. The Semitic Web depends on informal communication to advance collective exercises, alongside other normal employments of interpersonal interaction.

$\checkmark$ BRICS: The framework centers around the foundation of a computerized library net work, with the goal that data can be shared between clients in the social legacy area.

\section{SSDL gets SDL}

Artha concentrates more on the recovery of Artha data instead of giving advanced data an open door for clients to share information. Financial advanced libraries created after this need.

\section{* Improvement of Social Meaning Information}

This is accomplished by joining the Semantic Web with joint effort devices on the Web. The Social Semantic Digital Library conforms to existing highlights of Semantic Digital Libraries by giving a chance to contribute data. Web 1.0 created as a community oriented stage, where individuals can share and offer data, that is, Web 2.0. Web 2.0 was advanced by Tim O'Reilly around the year 2005 [14]; It offers basic Internet clients the chance to trade, meet and offer data like never before previously, and incorporates ideas, for example, sites, wikis, person to person communication and that's only the tip of the iceberg.

$>$ Benefit

- People can engage in cooperative tasks with the assistance of these libraries, and accomplish incredible things likewise.

- Dissemination of data and individual encounters starting with one individual then onto the next.

\section{$>$ THELOSS}

- It might deliver beginner information by certain clients.

- It gives restricted insurance.

\section{>SSDL and FUTURE}

Social Earth Digital libraries (and Web 2.0) have made the web community and intuitive; However, one inadequacy that has gotten evident because of this development is data over-burden. Because of the ascent in the degree of Internet clients and in this manner their support on discussions, it has gotten hard to pinpoint the 'information' part of the substance. 
Another disadvantage of such libraries is that site pages are dynamic however not organized. Specifically, Web 2.0 devices empower substance to be measured on pages, yet not simply the substance. Definitely, the future will address these perspectives and the coming of Web 3.0 will make the Web all the more remarkable and organized. The essential idea driving Web 3.0 is 'metaphysics', which Thomas Gruber characterized as 'express particular of the idea'. Another future development that is significant for what's to come is that advanced explanation will be related with physical items throughout everyday life: for instance, in a historical center. An utilization of this method may incorporate genuine virtual seizures at a specific area: for instance, regardless a real guided visit and afterward (whenever wanted) perusing through virtual reference data or other Gathering data about shows. . The future part of the social semantic advanced library is to improve client benefits by engaging UIs and person to person communication. Client personality and framework mechanization are significant key focuses in future social importance advanced libraries.

\section{CONCLUSION}

Conventional libraries have taken the state of an intuitive, available and proficient stage present to the client whenever of the day. More up to date types of advanced libraries, ie Earth Digital Library, have demonstrated to convey more important outcomes for the client. Further advancements of the Semantic Digital Library have built up the idea of contributing data and social cooperation among givers. Consequently, the future has a significantly more encouraging and effective instrument for taking care of data.

\section{REFERENCES}

[1]. Diane, V., 2006, When did the Web start? Developed Traffic, http://developedtraffic.com/2006/08/04/whendid-the-web-start/

[2]. Berners-Lee, T., Hendler, J., Lassila, O., 2001, The Semantic Web, Scientific American Magazine (May 17, 2001). http://www.sciam.com/article.cfm?id=thesemantic-web\&print=true.

[3]. Kruk, S., R., Haslhofer, B., Kneževic, P., 2007, Tutorial 7- Semantic Digital Libraries, JCDL 2007

[4]. Lagoze, C., Krafft, D., B., Payette, S., Jesuroga, S., 2005, What Is a Digital Library Anymore, Anyway? D-Lib Magazine November 2005, Volume 11 Number 11 , http://dlib.org/dlib/november05/lagoze/11lagoze.html

[5]. Borgman, C., L., 2000, Digital libraries and the continuum of scholarly communication, Journal of Documentation, 56 (4), pp. 412-430

[6]. Borgman, C., L., 1999, What are digital libraries? Competing visions, Information Processing \& Management, pp. 227-243,

[7]. Celino, I., Turati, A., Della Valle, E., and Cerizza, D. (2006). Squiggle Med: Semantic search for medical digital library, Technical report, CEFRIEL. 